\title{
AVALIAÇAO CLINICA DO VALOR TERAPEUTICO DO BARBEXACLONE INCLUINDO DETERMINAÇÃO DE NIVEIS PLASMATICOS DO BARBITURICO
}

\author{
TELMO TONETTO REIS \\ MANOEL SOARES MAIA FILHO \\ PEDRO CELSO CECHINI
}

Considerando o que é atualmente publicado na literatura médica, os trabalhos de investigação e análise de dados podem ser orientados dentro de duas áreas distintas, ambas válidas: a) a investigação que se desenvolve num campo estritamente formal, orientada pelo elevado indice de monitorização ao qual os pacientes podem ser submetidos; b) a avaliação e compreensão objetiva do comportamento de pacientes, com mensuração dos resultados captados pela acuidade do clínico. Neste último caso, é fundamental que as observações realizadas procurem traduzir um pouco mais do que uma simples "impressão pessoal". No que diz respeito a este item e no caso do tratamento de pacientes com epilepsias, esta "impressão pessoal" poderá ser consequência daquilo que diariamente é executado na prescrição rotineira de drogas anticonvulsivas. É provável que nesta área de atuação desenvolva-se, algumas vezes, um trabalho não muito racional. Desenvolver planos de pesquisa através da obediência a parâmetros muito elaborados (a), é raramente factível em nosso meio. Os programas de investigações que seguem o item $b$, mais modestos, mas não menos importantes, deverão traduzir resultados que "a priori" tenham subsistido a suficiente estadiamento clínico. Então, o trabalho de observação clínica e coleta de dados para fins de apurar resultados em terapêutica antiepiléptica, deve apoiar-se em adequada "atividade profissional".

Como premissa, existe a necessidade de definir-se com maior exatidão possivel o tipo de doença ou de forma de epilepsia a ser tratada. É necessário um melhor controle dos efeitos dos produtos prescritos, raciocinando-se em termos de absorção, metabolismo e excreção das drogas em estudo e isto significa a necessidade de considerar, também, as funções digestivas, hepática e renal de nossos pacientes. Dentro de programas de avaliação de resultados terapêuticos organizados de maneira menos complexa, parece-nos fundamental a determinação dos níveis plasmáticos das drogas em estudo. Este tipo de exame laboratorial é tanto mais indispensável quando o paciente recebe mais de uma droga como tratamento ${ }^{1}$. Nestes casos, é básico existir um melhor entendimento das "interações" medicamentosas, produzindo alterações metabólicas para

Trabalho da Clínica Neurológica e Neurocirárgica de Porto Alegre (RS), apresentado ao XIII Congresso Nacional de Neurologia, Psiquiatria e Higiene Mental (Curitiba PR, 28 de outubro a 02 de novembro de 1977). 
mais ou para menos, com repercussão nos níveis plasmáticos das drogas. Aqui encontrar-se-ão muitas das explicações para certos casos de intoxicação medicamentosa, quando as doses dos produtos usados encontram-se dentro de limites considerados adequados. Por outro lado, estímulos de indução enzimática, poderão acelerar a metabolização da droga, tornando sem efeito a ação de um tratamento prescrito em doses habituais.

Com estas considerações, apresentamos as nossas impressões referentes ao uso do barbexaclone (ciclo-hexil-metilaminopropano-fenil-etil-barbiturato), referentes ao tratamento de um grupo seleto de epilépticos ${ }^{2}$. Deixamos claro que vão aqui registradas as impressões clínicas iniciais referentes à eficácia da droga. Ampliando a elaboração de nosso plano de trabalho, num subgrupo de pacientes, realizamos a medida dos níveis plasmáticos do barbitúrico. Estas provas laboratoriais permitem ao observador, de forma mais ampla, comprovar se o paciente toma a medicação, verificar o efeito terapêutico de uma certa concentração plasmática, assim como a farmaco-cinética da droga, isto é, as diferenças de concentração plasmática produzidas por determinadas doses do medicamento $\mathbf{2 . 3 , 4}^{\text {. }}$

\section{MATERIAL E METODOS}

Participaram de nossa observação 70 pacientes que apresentaram duas ou mais crises de convulsões tipo grande-mal. Estes pacientes, 36 mulheres e 34 homens, participaram de um plano de trabalho e observação durante 18 meses. Considerando-se a idade de 15 anos como limite, 52 pacientes eram crianças e 18 adultos. Neuhum tinha idade superior a 55 anos. Ao exame neurológico nenhum dos pacientes apresentava evidências de lesão orgânica do sistema nervoso central. As alteraçós eletrencefalográficas encontradas, em exames realizados em vigilia e sono induzido, em todos os pacientes, em periodos intercríticos, foram as seguintes: focos convulsivos temporais, 12 casos; atividade irritativa não focal, 28 casos; atividade theta predominante em nivel temporal (adultos), 10 casos; disritmias lentas generalizadas de grau moderado, 20 casos.

Esclarecemos que este grupo de pacientes foi selecionado procurando-se nos mesmos duas características principais: 1) não apresentarem doença epiléptica crônica; 2) não apresentarem sinais de lesão orgânica do sistema nervoso central ao exame neurológico.

Para um grupo nestas condiçס̃es clínicas pareceu-nos mais objetivo e real, obtermos informações do controle das crises com o uso de uma só droga. Assim seria possivel avaliarmos as concentrações plasmáticas desta droga. Também com o uso de um único produto anticonvulsivo seria mais real a observação de para-efeitos causados pelo medicamento.

Para a observação de para-efeitos, solicitamos aos pacientes informar a presença ou não dos seguintes sinais e sintomas: 1) sonolência leve: 2) sonolência excessiva com algum prejuizo para a atividade laborativa; 3) insônia; 4) alguma manifestação de natureza alérgica; 5) irritabilidade. 
Durante o periodo de observaça de 18 meses a que foram submetidos os pacientes, foram realizados, em cada caso, por duas vezes, hemograma, hemossedimentaçáo e contagem de plaquetas.

A droga barbexaclone * foi administrada nas seguintes doses: $5 \mathrm{mg}$ por quilo de peso por dia para pacientes até 15 quilos; $4 \mathrm{mg}$ por quilo de peso por dia para pacientes até 35 quilos; $3 \mathrm{mg}$ por quilo de peso por dia para pacientes acima de 35 quilos. A medicação foi administrada sempre em duas tomadas diárias.

Em 20 pacientes realizamos a mensuração dos níveis plasmáticos de barbitúrico **, o que foi realizado pelo método de Goldbaun, considerando como níveis plasmáticos normais 10 a 30 microgramas por $\mathrm{ml}$. Os resultał̉os desta avaliação laboratiorial encontram-se no gráfico 1. Este gráfico exclue uma paciente que tomou a droga em estudo durante várias semanas irregularmente; em uma das dosagens realizadas nesta paciente, os níveis plasmáticos da droga foram nulos.

\section{RESULTADOS}

O barbexaclone, associaçåo de fenil-etil-barbiturato com um estimulante do sistem; nervoso central, conhecido pela sigla CHP foi empregada como anticonvulsivo unicu no tratamento de 70 pacientes selecionados, tendo como elemento fundamental terem apresentado duas crises convulsivas tipo grande-mal e um exame neurológico normal. Acompanhamos estes pacientes durante o período de 18 meses, tempo que durou esta avaliaçåo clínica, mediante visitas trimestrais.

Para fins de avaliaçåo de resultados, foram excluídos do grupo inicial 17 pacientes: 14 năo compareceram ao ambulatório conforme o controle programado; dois pacientes, com 5 e 5 anos e meio de idade, desenvolveram intenso quadro de irritabilidade, o qual somente aliviou com a suspensão do medicamento; 1 (uma) paciente foi excluída do grupo, para fins de mensuração de resultados, pois tomava a medicação irregularmente, tal como confirmado pessoalmente.

Assim, a avaliação da potência anticonvulsiva da droga e de seus para-efeitos, inclui um grupo de 53 pacientes, os quais concluiram a avaliaçăo. Deste grupo, dois pacientes, de 8 e 12 anos, mostraram-se refratários ao uso do barbexaclone como controlador das crises, em regime mono-terapêutico. Trata-se dos casos 4 e 13 do gráfico 1; em ambos as crises cederam com a instituiçåo de regime múltiplo. Os demais pacientes tiveram suas crises completamente controladas, isto é, aproximadamente $96 \%$ do grupo, percentual este que nos parece bastante expressivo.

Os para-efeitos observados neste grupo de 53 pacientes ocorreram principalmente em crianças abaixo de 9 anos de idade, sendo a irritabilidade e a sonoléncia os mais frequentes. Assinalamos: sonolência leve, 10 casos; sonolência excessiva com algum prejuizo para a atividade iaborativa, 3 casos; insônia, 2 casos; irritabilidade, 5 casos (em dois pacientes houve necessidade de suspensăo da droga). Não foi assinalada qualquer manifestação alérgica.

* Barbexaclone (Maliasin) fornec:do por Knoll S/A Produtos Químicos e Farmacêticos.

* A determinação dos níveis plasmáticos de barbitúricos foi feita pelo Laboratório Bio-Ciências Lavoisier (São Paulo, SP). 
Com excessão dos dois casos de manifestações de irritabilidade acentuada e persistente, nos demais os para-efeitos foram de observaçăo temporária, aliviando com pequenos ajustes na dosagem da droga e apos a terceira semana de tratamento. Em nenhum caso encontramos alterações significativas no hemograma, hemossedimentação e na contagem de plaquetas.

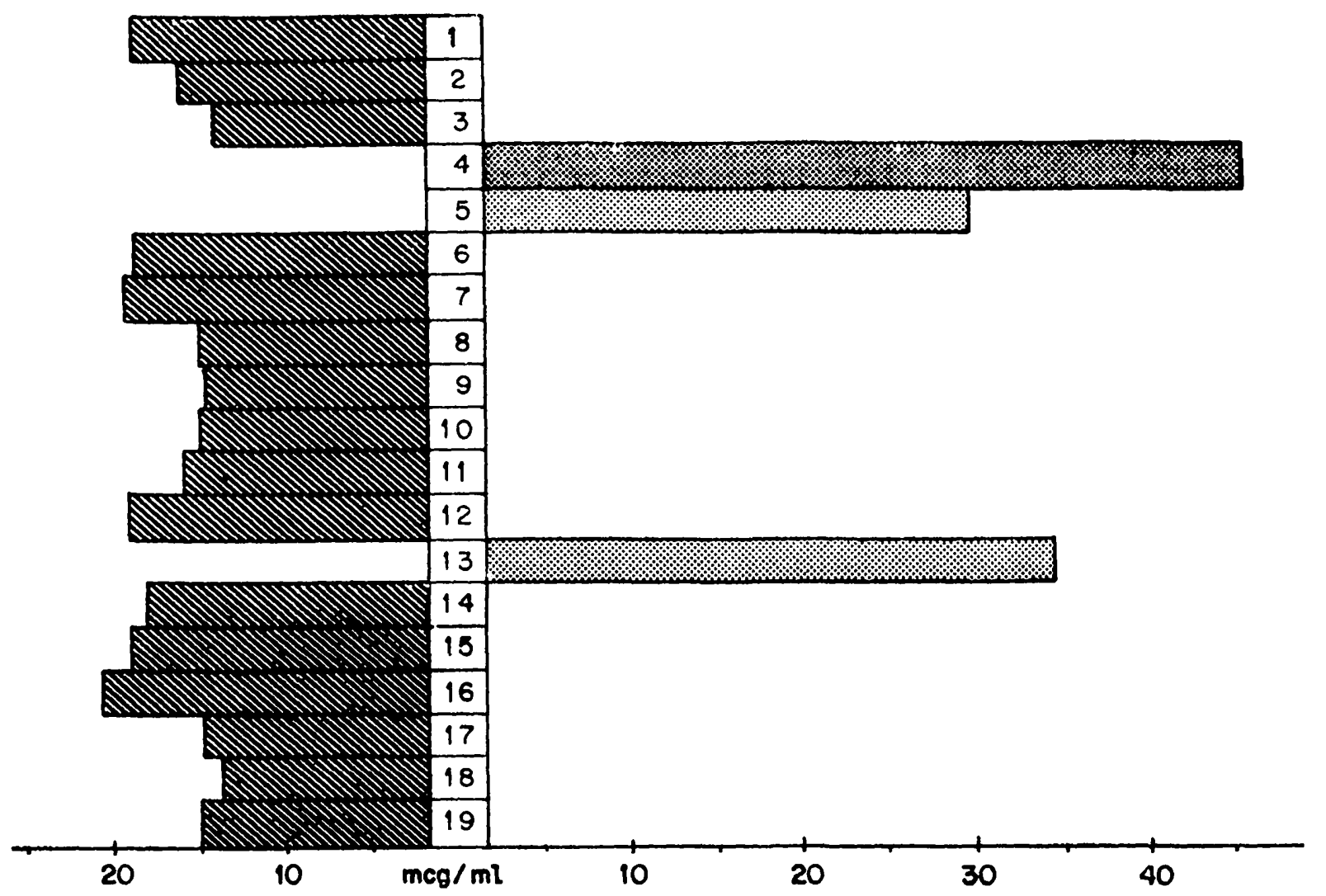

Grafico 1 - Valores da concentracão plasmática de barbitúrico em 19 casos. Os valores rormais para a concentraço plasmatica sao de 10 a 15 microgramas/ml. A esquerda estão tabulados os resultados que estão dentro destes limites, a direita figuram os resultados a so microgramas/ml. Uma paciente que tomava a medicacao irregularmente foi excluida.

\section{COMENTARIOS}

Julgamos que a maior contribuição deste trabalho reside na avaliação dos dados do gráfico 1, onde estão tabulados os valores dos níveis plasmáticos do barbitúrico. Níveis sanguíneos terapêuticos ideais foram alcançados em todos os casos, com dosagens que não foram superiores às que estabelecemos no início do trabalho. A dose máxima que administramos aos pacientes de número 4 e 13, não foram superiores a $300 \mathrm{mg}$, nas 24 horas. Em ambos, mesmo com niveis plasmáticos ao redor de 40 microgramas por $\mathrm{ml}$ (limite inferior dos níveis considerados tóxicos), não foram observados sinais de intoxicação, nem alterações hematológicas. Vale mencionar o caso 5 , relativo a paciente de 33 anos, professora de curso primário em plena atividade de trabalho normal que recebia a dose total de $250 \mathrm{mg}$ de barbexaclone por dia. Uma paciente constituiu-se num soberbo exemplo de fonte de erro, quando se avaliam resul- 
tados, sem mensurar os índices plasmáticos da droga em estudo. Esta paciente, estudante universitária, somente declinou não tomar regularmente a droga que lhe fora prescrita, após a evidência laboratorial de índice nulo da droga anticonvulsiva no plasma. Evidentemente, após esta alerta a paciente mostrou-se extremamente cooperativa. No entanto, para fins de avaliação de resultados, ela foi excluída do grupo.

Para os 19 pacientes controlados com determinação de níveis plasmáticos do barbitúrico, obtivemos controle completo das crises em $89 \%$ dos casos, resultado este que nos parece, também, muito satisfatório.

RESUMO

São apresentados os resultados de um ensaio clínico usando barbexaclone (ciclo-hexil-aminopropano) associado com fenil-etil-barbitúrico, como único anticonvulsivante. Foram selecionados 70 pacientes dos quais 36 eram do sexo feminino e 34 do sexo masculino, sendo 52 crianças e 18 adultos. Todos apresentavam crises de epilepsia tipo grande-mal e tiveram duas ou mais crises antes de serem incluídos na pesquisa. Cinquenta e três pacientes foram observados durante 18 meses, dos quais $96 \%$ ficaram livres de crises neste período. Os niveis plasmáticos dos barbitúricos foram determinados em 20 pacientes. Nestes pacientes o controle completo das crises atingiu 89\%. A mensuração dos níveis plasmáticos dos anticonvulsivantes tem demonstrado ser um guia terapêutico útil e seguro no tratamento de epilepsia.

\section{SUMMARY}

Clinical evaluation of the therapeutic value of barbexaclone including the study of serum barbiturae levels.

The results of the use of barbexaclone (ciclo-hexil-aminopropan) in association with fenil-etil-barbiturate, as a single anticonvulsant drug in a clinical and therapeutic trial are reported. Seventy patients, 36 women and 34 men, 52 children and 18 adults, all of them with two or more epileptic grand-mal seizures at the begining of treatment, were selected. In 53 patients a complete 18 months follow-up observation was performed. In this group of patients, $96 \%$ of them were free of seizures during the observation time. In 20 patients the barbiturate plasma concentration was measured. For these patients, the effectiveness of the treatment was up to $89 \%$, in terms of complete control of convulsive crises. The measurements of the plasma level of anticonvulsants has shown to be most useful and a safe therapeutic guide in the treatment of epilepsies. 


\section{REFERENCIAS}

1. BUCHTHAL, F. \& LENNOX-BUCHTHAL, M. A. - Phenobarbital: relation of serum concentration to control of seizures. In Anti-epileptic Drugs - D. Woodbury, J. Perry \& R. P. Schmidt ed. Raven Press, New York, 1972, pág. 335.

2. BRAgATTI, J. H.; CALEFFI, G. H. \& PRENNA, F. J. - Ensaio clínico com o uso de um novo anticonvulsivo (barbexaclone). Arq. Neuro-Psiquiat. (Săo Paulo) $35: 277,1977$.

3. BRAIN, R. - Paroxysmal and convulsive disorders. In Brain's Diseases of the Nervous System - John. N. Walton ed, Oxford University Press, Oxford, 1977, pág. 1094.

4. KILOH, L. G. \& OSSELTON, J. W. - Epilepsy. In Clinical Electroencephalography - L. G. Kiloh \& J. W. Osselton ed. Butterworths, London, 1961, pág. 29.

5. OLIVEIRA, C.; FERNANDES, I. \& LIMA, J. M. - Ensaio clínico com barbexaclone nas epilepsias. Arq. de Neuro-Psiquiat. (Såo Paulo), 35:68, 1977.

6. HASS, H. - Pharmakologische Aspekte zu einem neuen Antiepileptikum Maliasin. Gemeins. Tagg. d. dtsch., oesterr. u. schweiz. EEG-Ges.u. d. Sekt. d. internat. Liga gegen Epilepsie, Zuerich, 28-30, 3, 1963.

7. PENNIN, H. - Bericht ueber die klinische Pruefung von Maliasin. G Gemeins Tagg. d. dtch., oesterr. u. schweiz. EEG-Ges.u.d.Sek.d. Internat. Liga gegen Epilepsie, Zuerich, 28-30,3,1963.

8. HAAS, H. - Der wirkungsmechanismus des 1-1-Cyclohexyl-2-methylamino-propan, 5.5phenylaethylbarbiturats und seine Eignung als Antiespilepticum. Vergleichende Studien mit Phenobarbital. Arzeneimittel-Forsch., Aulendorf 13:613, 1963.

9. PENIN, H. - Wirkung und indikation eines neuen antiepilepticus. Dtsch. Med. Wschr. $89: 1683$, 1964.

10. KRUEGER, H. J. \& SCHWARZ, H. - Klinische Mitteilung zur Epilepsie: Therapie mit Maliasin. Med. Welt, 14:690, 1965.

11 JOVANOVIC. U. J. - Die sich as dem natuerlichen Schlaf der Epileptiker ergebenden therapeutischen Konsequenzen. Nervenarzt $39: 199,1968$.

12. BECKER, B. - Erfahrungen mit dem Antiepileptikum Maliasin. Ed. Welt. 9:577. 1968.

13. HEUBECK, H. - Bericht ueber klinische Erfahrungen mit einem neuen Antiepileptikum. Fortschr. Med., 86:2776, 1968.

14. CANGER, R. - Die Behandlung der Epilepsie mit Maliasin. Rass, neuropsichiatr. (Salerno) $21: 1,1967$.

15. CANGER, R. \& UAHL. L. - Die Behanglung der Epilepsie mit Maliasin. Nervenarzt $39: 476$, 1968.

16. SCHIEFER, I.; BREYER, F. J. \& SCHEFFNER, D. - Erfahrungen mit Maliasin bei der Behandlung anfallskranker Kinder Med. Welt 44:2420, 1968.

17. TCHICALOFF, M. \& PENNETTI, F. - Maliasin, ein neues Antiepileptikum Med et Hyg. (Geneve) H. 1198, 1970. 